\title{
Competency Based Approach: Modeling and Implementation
}

\author{
https://doi.org/10.3991/ijet.v15i02.11295
}

Malika Sedra $\left({ }^{凶}\right)$, Samir Bennani

Mohammed V University, Agdal, Morocco

malikasedra@gmail.com

\begin{abstract}
The expansion of computer networks has at the same time given impetus to the distance learning environments. E-learning systems are also advanced and more efficient. However, these platforms offer such complex teaching functionalities that designers find themselves poorly equipped to succeed in their engineering processes. This article presents a tool that makes it easier for designers to produce educational content according to the Competency-Based Approach (CBA). We propose an implementation of the CBA after its modeling via ontology. Our module can be grafted to any author system oriented pedagogy based skills. We have advocated for Service Oriented Architecture as a software solution to model our business process that consists of a set of interconnected services that are modeled and implemented. The proposed system is the result of a coordination of, services, incorporating the order of competences explained by a distance education, which integrates and interacts according to an orchestration plan.
\end{abstract}

Keywords - Competency-based approach (CBA), ontology, modeling, Service Oriented Architecture (SOA), orchestration \&choreography

\section{$1 \quad$ Introduction and Problematic}

In e-learning, the use of web technologies in the field of education offers opportunities to implement new didactical intentions in different learning contexts. However, the quality of these IT environments depends on their ability to provide designers with instructional engineering tools tailored to their needs.

The use of most authoring systems is complicated by technical difficulties in taking control or operating. Furthermore, assistance which provides the appropriate educational support for designers is not sufficient in some EIAHs and often does not exist in non-pedagogical applications. The addition of a tool to support systems used in educational settings seems to us a solution on the one hand to overcome technical difficulties, and on the other hand, to accompany the pedagogical designer by offering him a system agreed to his knowledge and his technological performance.

The competency-based approach CBA is a trend that we will adopt to develop our proposal. Our goal is to design a learning production tool according to the CBA that can properly reduce the efforts of pedagogical designers with didactic intentions 
based on skills. Using a knowledge base, founded on the ontology that we previously built to support the CBA [1]. In order to model our business process, we have recommended the Services Oriented Architecture (SOA) [13] as a software solution which enabled us to identify the services required and define their scheduling in line with the logic of the business process. In addition, we offer a composite service that integrates the process including all stages of designing educational content. This service can be implemented in any online training system. Furthermore, interoperability and reuse must be guaranteed. In order To model it, we opted for web services. Indeed, web services do not impose a specific programming language, which guarantees a better operability. Services are available, reusable and adaptable to meet new business needs. To implement this vision, we propose a service composition model to meet business needs.

\section{Service Oriented Architecture}

The term architecture is described [2] as a set of fundamental concepts or properties of a system in its environment. The relations between its elements and the principles of their conception and its progress translate these concepts. The evolution of the information system is marked by profound changes in architectures and uses. Thus, the paradigm service is needed and its importance has increased with the emergence of web services and SOA [14]. The service approach considers services as stand-alone software resources that can be published and shared, discovered and dynamically assembled to produce applications. We consider that this approach aims at greater flexibility, better reusability of the elements that make up a system and a stronger alignment between the Information System (IS) and the business. In addition, the service approach leads to a new vision according to which an I.S. is a set of services and service compositions. In this context, defining, designing and producing service compositions become essential topics. The implementation of SOA-based applications [3] is based on a life cycle composed of three phases: preliminary phase, modelling phase, and assembly phase. Two types of actors intervene in these three phases: the service provider and the customer who is the consumer of service.

\subsection{The components of the SOA}

A service-oriented architecture is a way of designing service-oriented or servicebased business applications from a service catalog "see Figure.1". The application becomes a composition of services to be used in other applications, that is to say a part of the application logic that is not exclusive to the application. [4] The use of an inventory of services renders the overall reuse perspective at the enterprise level predominant. 


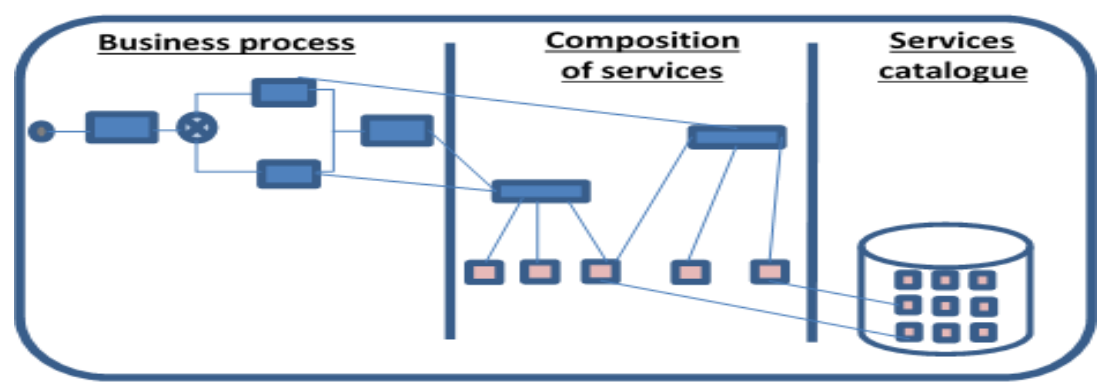

Fig. 1. Business Process and Service Composition

The operation of SOA can be summarized in the paradigm "Find, Bind and Execute». In fact, a consumer asks a directory for all the services available to him and which correspond to his criteria. For its part, the directory provided to the caller a contract and an address "endpoint" of the service. Thus, [5] we distinguish three essential components of this architecture "see Figure 2":

- Service Consumer: This is a software component that requires a service and binds to it dynamically at runtime. It is a service user who discovers and uses the services published in the service registry

- Service Provider: This is the service, an addressable entity in a network that accepts and executes requests from different consumers. The service provider publishes the services and their descriptions in a service registry.

- Service Register (Directory): This is a directory on the network containing the list of services. It accepts the list of contracts presented by service providers and exposes it to potential consumers. It is also defined as the discovery component that provides the service discovery and publishing interfaces.

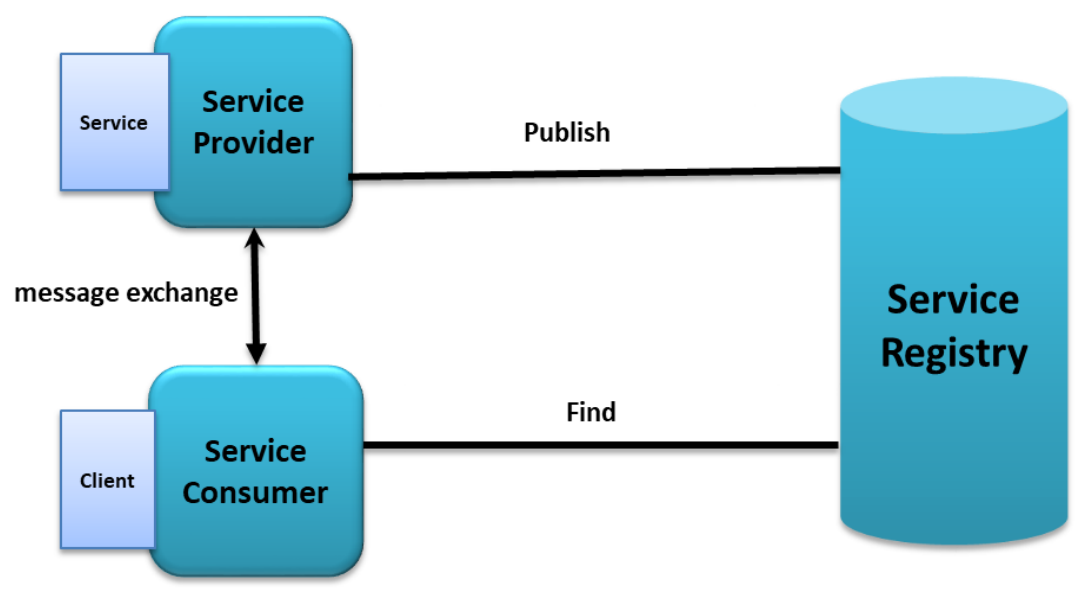

Fig. 2. . Service Oriented Architecture 
To build a service-based application, it should be specified whether the services that implement the application bricks already exist or if they should be designed as a way to avoid redundancy and promote the reuse of available services. Service discovery is essentially implemented by adding metadata to the service contract. Thus, this contract must contain metadata that clearly communicate the objectives and capabilities of the services. On the other hand, the implementation of the service contract requires the use of standards to make the service contract discoverable. When using web services, metadata can be added in an unstructured way to the services as comments in the WSDL or in the XML schema. They can also be added in a standardized way with WS-Policy [6]. Service discovery can be automated using Universal Description Discovery and Integration (UDDI) [7] to obtain information about the description of services stored in the service registry.

\subsection{The composition of services}

Service composition is the mechanism that allows the integration of services into an application [8]. The result of this composition is a service, called a composite service. Implementing a service composition application follows several steps that allow the incremental shift from an abstract specification to a concrete composition of services [9]. The service composition implements a process, which is composed of a set of activities and a control flow. For a composition of services, each component activity corresponds to the invocation of a service and the control flow defines the conditions for the execution of these activities, i.e. the order of invocation of the collaborating services and the different interactions between them. Two compositional approaches are possible "see Figure 3": Service Orchestration describes the centralized vision of a service composition and Service Choreography describes, from a global point of view, how a set of services collaborate to achieve a common goal.

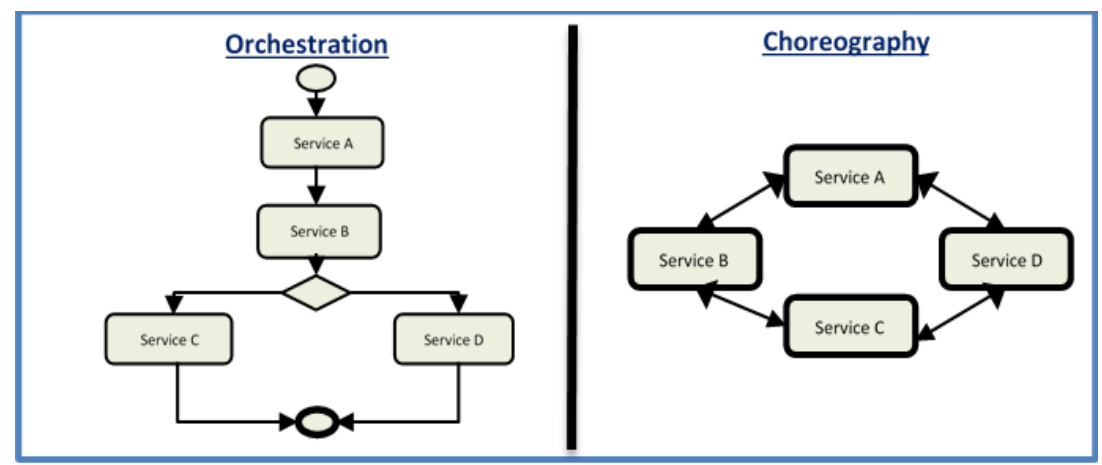

Fig. 3. Service composition approaches

Indeed, the businesses processes are modeled via orchestrations that will prevent the services need to know each other to achieve a business process and thus avoid strong connection between services. 


\subsection{Service orchestration}

Orchestration promotes independence of services and ensures that services do not directly call other services. It handles these calls as part of a business process defined through an orchestration plan. This plan includes the order of execution of messages and business processes. In orchestration, the orchestrator is responsible for composing and controlling interactions between departments. This element coordinates the operations in a centralized way between the different partners. The orchestration presents the internal vision of the composite service provider resulting from this composition. The execution of the service orchestration is controlled by a central entity called the execution engine that manages the invocation of the various services involved in the composition according to the logic defined by the workflow. In the following, we will define our business process. Then, we will introduce the Business Process Modeling Notation (BPMN) [11] to be able to model the services as well as their orchestration.

\section{$3 \quad$ Proposal and Modeling}

\subsection{The modeling of the proposed service}

To support and technically assist instructional designers, we have proposed a tool that provides guidance in instructional design based on APC. When designing a learning object related to a skill, our module performs a search and presents the result to the designers: the resources relevant to the competency in question. Its implementation is the core of our research. We therefore propose to model CBA as a business process. Composed of a set of interrelated services, which are designed to deliver a result. Current e-Learning systems need to integrate new approaches to improve the quality of learning. To put these capabilities into practice as a business process, we opt for an SOA architecture, where we define services using the BPMN language, as well as their interactions using an orchestration plan. It is a service that will use as an input the targeted competence and the level of the learner's skill required, in order to produce an output of adequate pedagogical resources [see Figure4].

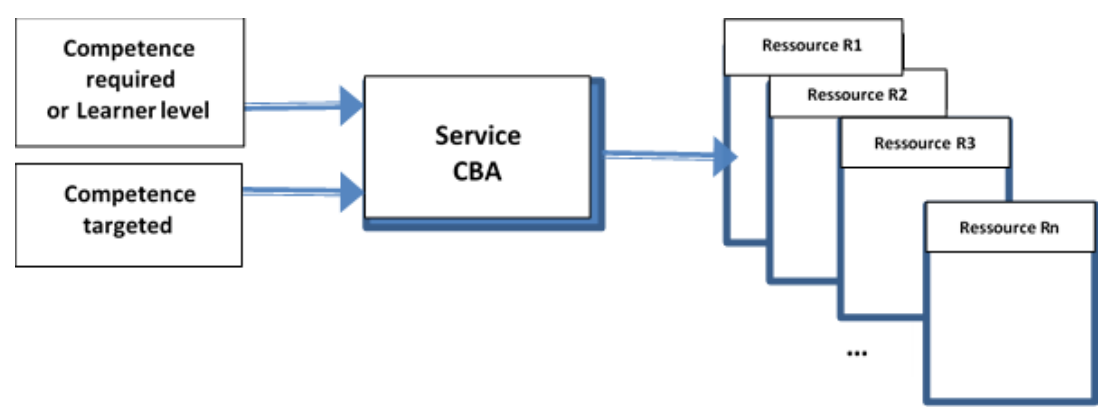

Fig. 4. Description of the proposed service 
The proposed service is composed of three other services that are scheduled and designed with a view to making the CBA a reference framework. The invocation and execution of these services provide the desired result. To meet the logic of our business process, the service integrates:

Service Skills Analysis (SSA) Ted competence elements. The work of acquiring these skills is done by consulting the skills reference system, designed in previous work [1], in order to be able to extract all the skills and sub-skills related to the targeted skill. Taking into account the learner's level as a required skill.

Correspondence Services (CS): this service is called by the SSA. It provides resources that reach a skill and connects each skill or sub-skill to the appropriate pedagogical resources (PR). The resulting teaching resources correspond to a learning activity. There are three possibilities: a competency developed from a PR, a competency developed from a sequence of PR and several parts of a competency developed in a RP [15].

\begin{tabular}{|l|}
\hline \multicolumn{1}{|c|}{ A skill $\mathbf{C} 1=$ PR1 } \\
\hline Or A skill $\mathrm{C} 1=\mathrm{PR} 1+\mathrm{PR} 2+\ldots+\mathrm{PRn}$ \\
\hline Or skills $\mathrm{C} 1+\mathrm{C} 2+\ldots \mathrm{Cn}=\mathrm{PR} 1$ \\
\hline
\end{tabular}

Resource Scheduling Service (RSS): it presents the sequential order of all pedagogical resources conducive to the development and acquisition of a targeted skill based on the results produced by the previous services

To master the process of the proposed service, we intend to graphically represent its business logic. We opt for the BPMN standard, which offers a set of standardized graphical elements and a grammar for their manipulation.

\subsection{Business process modeling: BPMN}

BPMN (Business Process Modeling Notation) is a standard that provides a set of standardized graphic elements and a grammar for their manipulation [10]. It defines a business process diagram (BPD), which is based on a technique adapted to the creation of graphical models of business process operations. Our BPMN model of the proposed service is the result of coordination between several other services [see Figure 5]. The latter can construct the object of an orchestration plan modeled in BPMN and translated into an executable language BPEL. 


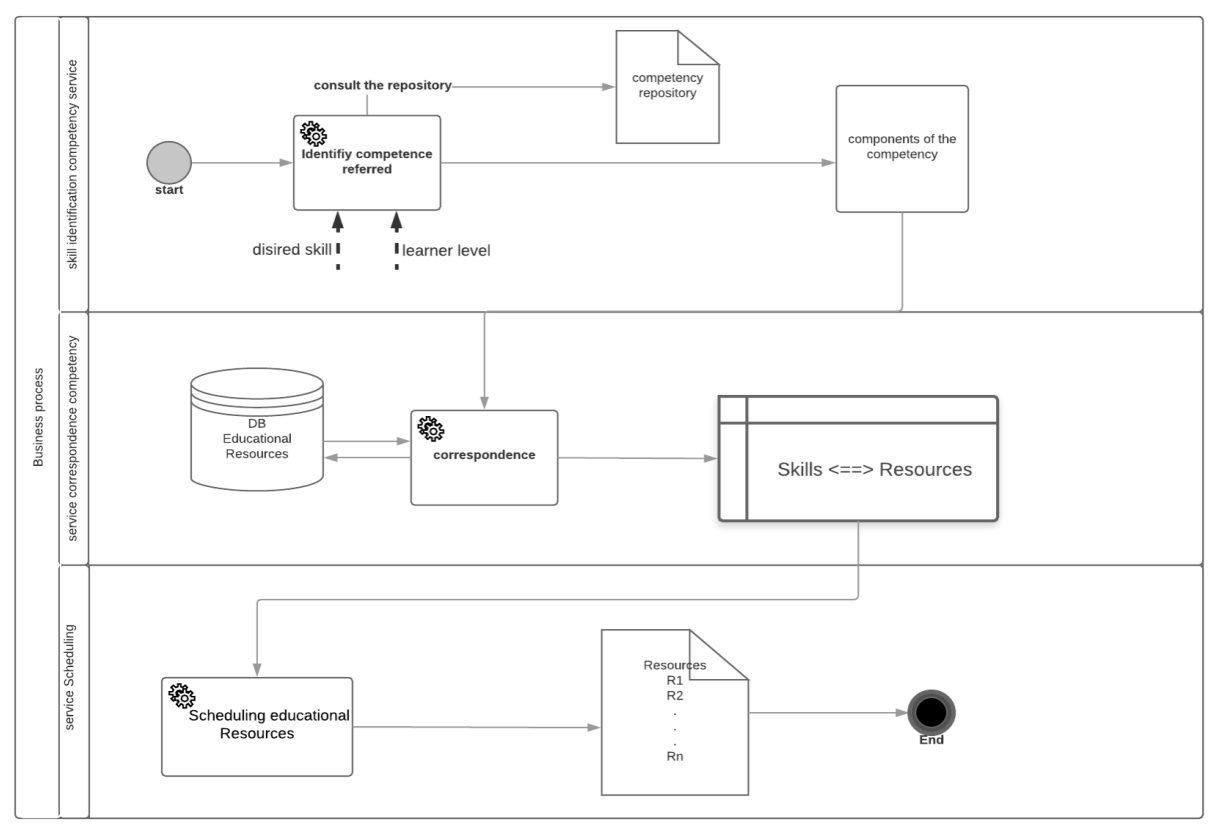

Fig. 5. Intervening Services by Business Process

\subsection{The business process execution language}

The orchestration of services requires the development of an execution language that can be understood by software agents. We have chosen BPEL (Business Process Execution Language) [12], which is currently the best-known specification for the orchestration of Web services. We were able to describe the service composition of our solution (see Figure 6) through the business process. We chose BPEL for its ability to manage the execution of the service composition, the realization of links with partner services. At the same time, it allowed us to invoke the functionalities provided by these services, to receive the answers and, depending on the logic of the business process, to invoke the next activity.

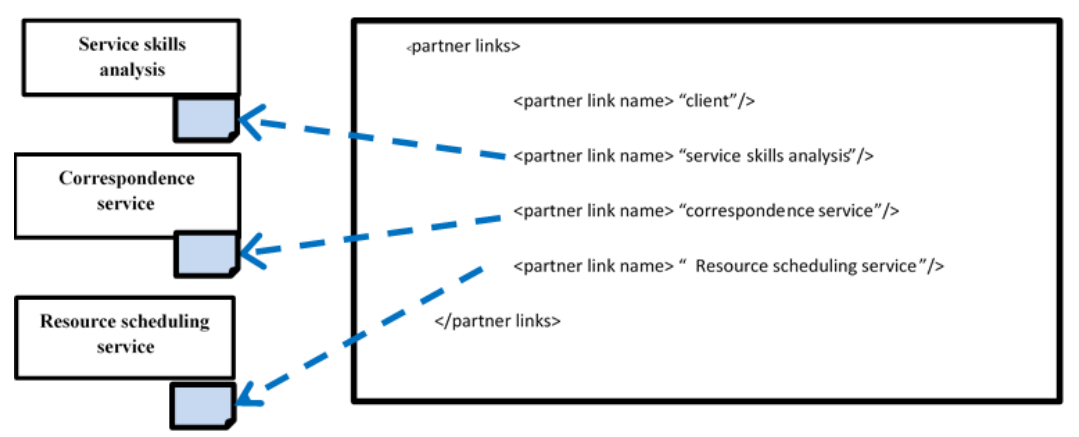

Fig. 6. Sample BPEL Document - Service Composition Definition - 


\section{Conclusion and Perspectives}

Currently, many education systems provide opportunities for designers to implement new didactic intentions in their learning process. However, these actors face technological difficulties in carrying out educational activities and remain dependent on support and technical assistance. Indeed, several studies have approached the assistance of pedagogical designers from different angles. Our vision is different in terms of the approach adopted, the architecture recommended and the concepts implemented. Our system is a support tool designed to be grafted onto an authoring system, and is presented as the recommendation of an organized set of resources concerning a skill to be acquired: the system selects the relevant resources and proposing them to the designers in the order in which these PR will be addressed during the learning activity relating to the skill in question. In this context we offer a composite service and its modeling involves resources whose specifications comply with the CBA. This service involves a set of services to achieve the result.

As perspectives of our work, on the one hand, we will consider the implementation of the resulting service in an educational platform. This will allow us to have results to analyze and see the impact on the quality of the education system. On the other hand, this evaluation involves actors and generates interactions that produce traces. These traces can be intercepted and analyzed and will then be used as a means of assessing the relevance of our system and making the necessary adjustments.

\section{$5 \quad$ References}

[1] Sedra M., Bennani S. (2018) "Ontology of the CBA: Towards Operationalization and Implementation" .Proceedings of the Mediterranean Symposium on Smart City Applications SCAMS 2017: Innovations in Smart Cities and Applications pp 87-94. Lecture Notes in Networks and Systems, vol. 37. Springer, Cham. https://doi.org/10.1007/978-3-319-74500$\underline{8} 8$

[2] ISO/IEC/IEEE-42010, Systems and software engineering - Architecture description (DRAFT), 2011, available on: http://www.iso-architecture.org/ieee-1471/. https://doi.org/ 10.1109/ieeestd.2011.6129467

[3] AL-Smadi, Mohammad and Guetl, Christian. 2011." Service-oriented flexible and interoperable assessment: towards a standardized e-assessment system". International Journal of Continuing Engineering Education and Life-Long Learning. 21 (4): pp. 289-307. https:// doi.org/10.1504/ijceell.2011.042789

[4] .Mayer P., MDD4SOA - Model-Driven Development for Service-Oriented Architectures, Doctoral thesis, LMU Munich, Munich, 2010.

[5] "Basic Components of SOA" https://tutorialseye.com/basic-components-of-soa.html" Web Services Policy 1.5 - Framework, 2007, available on: http://www.w3.org/TR/wspolicy/\# tocRange

[6] Bellen Ward, Bos David," UDDI Universal Description, Discovery and Integration", 19/03/2014, http://cs.ulb.ac.be/public/_media/teaching/infoh511/uddi-wsseminar1314.pdf. 
[7] Fatima Aladwan, Ahmad Alzghoul. " Service Composition in Service Oriented Architecture: A Survey", November 2018, available on: https://www.researchgate.net/publication/ $\underline{328889364}$

[8] Emma Fki. " Selection and flexible composition based abstract services for a better adaptation to the intentions of the users". Réseaux et télécommunications [cs.NI]. Université Toulouse 1 Capitole, 2015. Français. fftel- 01314946f

[9] Ali Arsanjani, Liang-Jie Zhang. "Design an SOA solution using reference architecture" published on 2007/updated: august 13, 2014.

[10] Business Process Model \& Notation BPMN , 5 avr 2017; availaible on : https://www.process.st/bpm

[11] "WSDL standsfor Web Services Description Language", 2019, https://www.guru99.com/ wsdl-web-services-description-language.html. https://doi.org/10.1007/978-1-4614-6170-8 100914

[12] Web Services Business Process Execution Language (WS-BPEL), 31 juil. 2015, https:// managementmania.com/en/ws-bpel-web-services. https://doi.org/10.1109/icsssm.2011.595 $\underline{9489}$

[13] Kong Xiangsheng " An SOA Approach to Virtual Classroom with Content Repurposing", International Journal of Emerging Technologies in Learning (iJET) Vol 9, No 1 (2014),pp. 61-65. https://doi.org/10.3991/ijet.v9i1.3064

[14] Papadakis, S., Kalogiannakis, M., Sifaki, E., \& Vidakis, N. (2018). «AccessMoodle Using Smart Mobile Phones". A Case Study in a Greek University. In A.Brooks, E. Brooks, N. Vidakis (Eds). Interactivity, Game Creation, Design,Learning, and Innovation. ArtsIT 2017, DLI 2017. Lecture Notes of theInstitute for Computer Sciences, Social Informatics and TelecommunicationsEngineering, vol 229, (pp. 376-385), Switzerland, Cham: Springer.

[15] Kalla Madhu Sudhana, V Cyril Raj, T Ravi. (2014). "Adaptation Oriented "Resource" Modeling for Course-based E-learning Environment" International Journal of EmergingTechnologies in Learning, (iJET) - Volume 9, Issue 1, 2014 pp 73-77 https://doi.org/ $\underline{10.3991 / \text { ijet.v9i1.3090 }}$

\section{Authors}

Malika Sedra is a PHD student in the Department of Computer Engineering, Mohammadia School of Engineers, Avenue Ibn Sina / B.P.: 65-Agdal -Rabat-Morocco (e-mail: malikasedra@gmail.com). Her current research project focuses on Modeling in Software Engineering \& e-learning Systems.

Samir Bennani is a PhD Professor in the Department of Computer Engineering, Mohammadia School of Engineers, Avenue Ibn Sina / B.P.: 65-Agdal -RabatMorocco (e-mail: sbennani@emi.ac.ma). He is appointed Deputy Director of Students and Academic Affairs in 2015. His interests are in: Modeling in Software Engineering (Merise, Object, MDA), Information system (Audit, ERP, SIAD) and Tele-teaching: content engineering, (Tutoring, evaluation, tracking)

Article submitted 2019-07-15. Resubmitted 2019-08-23. Final acceptance 2019-09-21. Final version published as submitted by the authors. 